\title{
Erratum to: Effect of flower perceptibility on spatial-reward associative learning by bumble bees
}

Shohei G. Tsujimoto ${ }^{1}$ Hiroshi S. Ishii ${ }^{1}$

Published online: 2 August 2017

(C) Springer-Verlag GmbH Germany 2017

Erratum to: Behavioral Ecology and Sociobiology

DOI 10.1007/s00265-017-2328-y

In the original version of this article, the name of Hiroshi S. Ishii was incorrectly presented as Hiroshi H. Ishii.

The original article was corrected.

The online version of the original article can be found at http://dx.doi.org/ 10.1007/s00265-017-2328-y

Electronic supplementary material The online version of this article (doi:10.1007/s00265-017-2354-9) contains supplementary material, which is available to authorized users.

\footnotetext{
Shohei G. Tsujimoto

s.tsujimoto.6411@gmail.com

1 Graduate School of Science and Engineering, University of Toyama, 3190 Gofuku, Toyama 930-8555, Japan
} 